\title{
Incidental Gall Bladder Carcinoma in Patients Undergoing Cholecystectomy in a Tertiary Care Hospital
}

\author{
Mangilal Choudhary ${ }^{1 *}$, Dilip Ramrakhiani²
}

${ }^{1 * R e s i d e n t ~ D o c t o r, ~ 2 P r o f e s s o r, ~ D e p a r t m e n t ~ o f ~ P a t h o l o g y, ~ S M S ~ M e d i c a l ~ C o l l e g e, ~ J a i p u r, ~ R a j a s t h a n, ~ I n d i a . ~}$

\begin{abstract}
Introduction: Incidental gall bladder carcinoma (IGBC) is an incidental finding of carcinoma diagnosed on histopathological examination of gall bladder specimen removed for benign gall bladder diseases. Gall bladder carcinoma is a highly malignant tumor with a poor prognosis. The incidence of IGBC is around $0.19-3.3 \%$ in the literature.
\end{abstract}

Aims \& Objectives: To determine the percentage of gall bladder carcinoma incidentally diagnosed during histopathological examination of cholecystectomy specimens done for benign gall bladder disease.

Material and Methods: This study included 450 cholecystectomy specimens which were removed, during June 14 to July 2015 in a tertiary care hospital. The clinicopathological findings of cases with incidentally detected gall bladder cancers were recorded; age, sex, presenting symptoms, presence of gall stones, histopathological spectrum, histologic grade and staging of tumours were included (as per 7th edition AJCC2010).

Results: A total of 450 patients underwent cholecystectomy, incidental gall bladder carcinoma was diagnosed Histo-

\section{INTRODUCTION}

Gall Bladder Carcinoma (GBC) is the 6th most common cancer involving the gastro intestinal tract but it is the most common malignant tumor of the biliary tract worldwide. Our study aims to determine the incidence of gall bladder carcinoma incidentally diagnosed during histopathological examination of cholecystetomy specimen done for benign gall bladder disease in a tertiary care hospital in the north Indian population of the Rajasthan state. Preoperative diagnosis of carcinoma of gall bladder is occurring in fewer than $20 \%$ of patients. Presenting symptoms are insidious and typically indistinguishable from those associated with cholelithiasis, abdominal pain, jaundice, anorexia, nausea and vomiting. The prognosis of GB carcinoma is very poor with less than $5 \%$ of 5 year survival rate. Diagnosis of GB carcinoma is difficult at an early stage because of a lack of specific sign and symptoms. We evaluated all consecutive cholecytectomies received in our Department of Pathology during one year period and compared our data to those reported in the literature. We also tried to detect common characteristics among this particular group of patients. pathologically in 3 cases $(0.67 \%)$. All 3 patients were females and the mean age was 38.33 years.

Conclusion: Prognosis of incidental gall bladder carcinoma is better, if diagnosed at an early stage.

Key Words: Incidental gall bladder carcinoma (IGBC), Cholecystectomy.

\section{${ }^{*}$ Correspondence to:}

Dr. Mangilal Choudhary,

Room No. A 101

Resident Doctors Hostel in Campus,

SMS Medical College, J.L.N Marg,

Jaipur, Rajasthan, India.

\section{Article History:}

Received: 02-09-2016, Revised: 28-09-2016, Accepted: 09-10-2016

\begin{tabular}{|l|c|}
\hline \multicolumn{2}{|c|}{ Access this article online } \\
\hline $\begin{array}{l}\text { Website: } \\
\text { www.ijmrp.com }\end{array}$ & Quick Response code \\
\hline DOI: & \\
10.21276/ijmrp.2016.2.6.008 & \\
\hline
\end{tabular}

\section{MATERIALS AND METHODS}

This study includes 450 cholecystectomy specimens in patients undergoing cholecysetomy, from March 2015 till the sample size is attained. The clinicopathological finding of cases with incidentally detected gall bladder carcinoma according to age, sex, presenting symptom, presence of gall stones and histologic grade and staging of tumor are included.

\section{RESULTS}

The observational study showed a total of 450 cholecystectomies performed during the study period of 1 year. Out of these, 3 cases were positive for carcinoma gall bladder by histopathology. Incidence of incidental carcinoma among all the routine cholecystectomies come for histopathology examination was $0.67 \%$. The age of patients at diagnosis ranged from 36 to 55years (mean age 38.33 years), 10.60 standard deviation and less than $0.001 \mathrm{~S} P$ value. All 3 cases were female. Majority of the patients were in fourth and sixth decade of life. The most common clinical complaints were pain in right hypochondria, nausea, 
vomiting and fever. A preoperative abdominal ultrasound was done in all the 3 cases reveal longitudinal sonogram of gall bladder show heterogenous echotexure irregular margin, thickening of wall and intra luminal multiple stones. All patients had symptomatic gallstones for which laparoscopic cholecystectomy were done.

Gross examination showed in all 3 cases that gall bladder was only mildly thickened to $0.7 \mathrm{cms}$ in fundus and body region and lumen filled with multiple stones of varying size. There was no proliferative lesion seen grossly. Histopathology examination

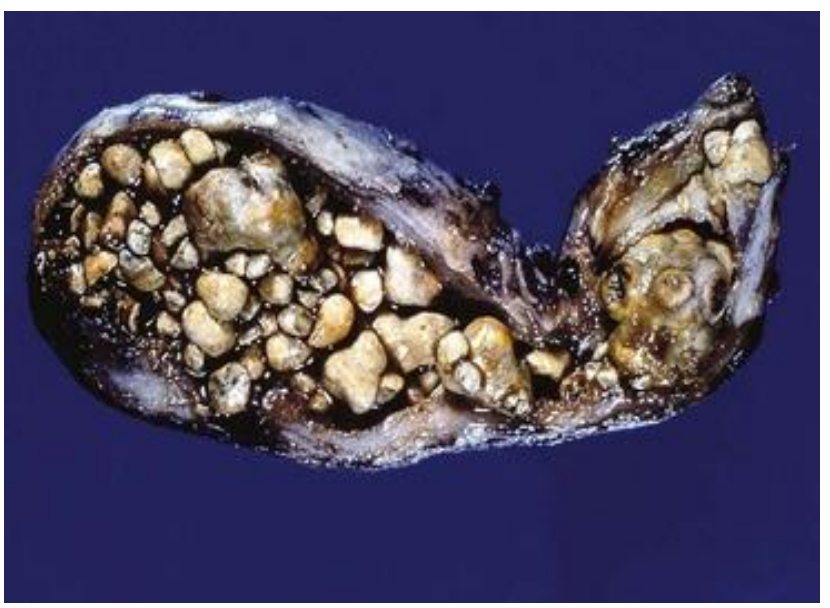

Fig 1: Gross Morphology: [Including whether gall stones present] FFSCO Gall bladder $\mathrm{ms} .9 \times 3 \times 2.5 \mathrm{~cm} .0 / S$ grey brown .C/S lumen filled with multiple stone, mucosa is brownish hypertrophic thickened neck region.

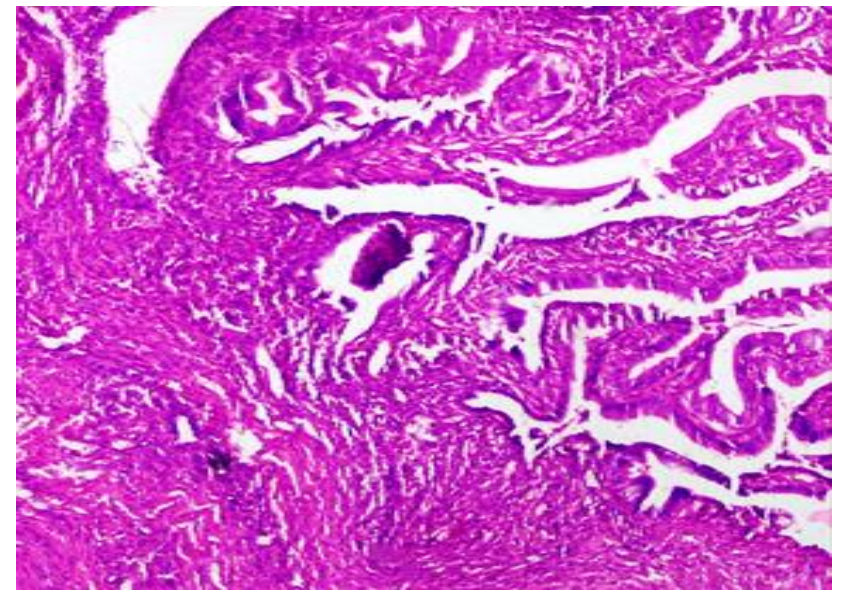

Fig 3: Microscopic features: Well differentiated adenocarcinoma. Tumour is infiltrating up to muscular layer. (Image 4x)
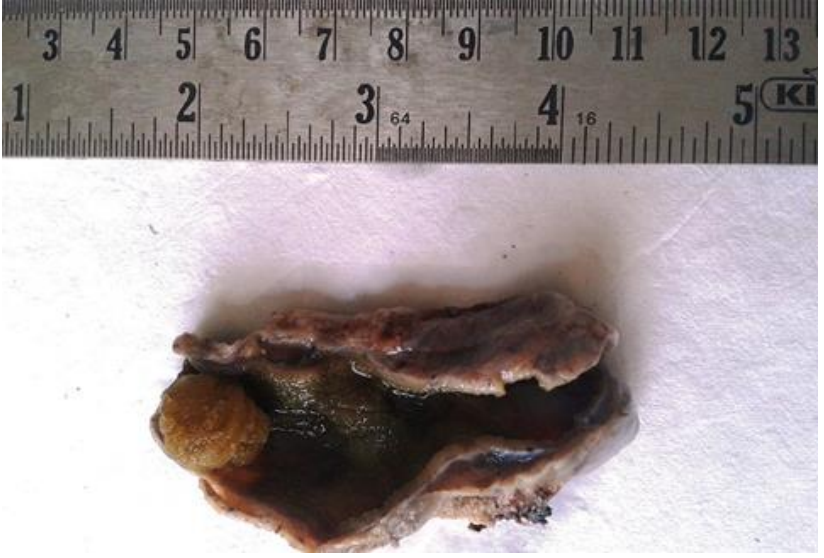

Fig 5: Gross morphology: A/C/O gall bladder $m s .7 \times 4 \times 2 \mathrm{~cm}$. $\mathrm{C} / \mathrm{S}$ shows hypertrophic wall show impression of stone showed 2 cases were Well differentiated adenocarcinoma in grade 1 with pT1b Nx Mx TNM (AJCC 2010) Stage and 1 case was Moderately differentiated adencarcinoma in grade 2 with pT2 Nx Mx TNM (AJCC 2010) Stage. Rest of the 447 cases incidence of cases according to their type were Chronic cholecystits with Cholelithiasis - 374 (83.1\%), Chronic cholecystits - 34 (7.56\%) Acute on chronic cholecystis - 20 (4.44\%), Xanthogranulomatous cholecystis - 5(1.11\%), Metaplasia and dysplasia and Acute cholecystitis - $3(0.67 \%)$, Adenoma - $2(0.44 \%)$ and Others - 6 $(1.33 \%)$

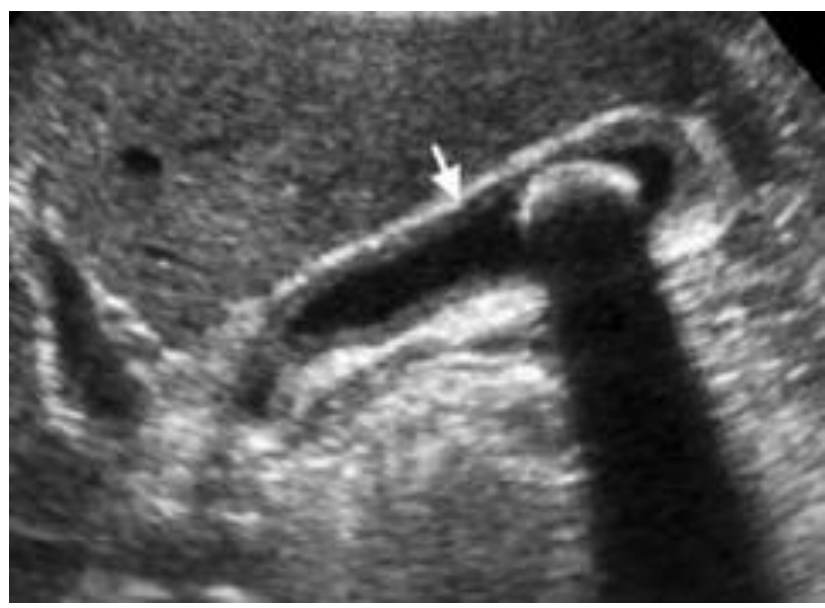

Fig 2: USG findings: Longitudinal sonogram of gallbladder shows heterogenous echotexure irregular margin slight wall thickening (arrow) and intraluminal multiple stones.

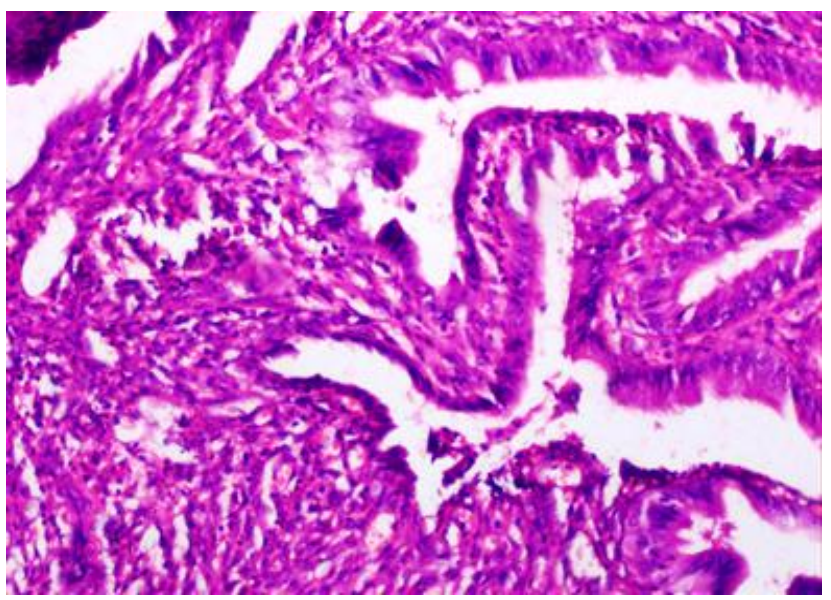

Fig 4: (Image 10x): Diagnosis including grade in case of $\mathrm{Ca}$ GB-Grade -1, Pathologic stage [AJCC2010] — pT1bNO MO

\section{DISCUSSION}

Carcinoma of gall bladder is a rare gastrointestinal malignancy however it is reported to be the most frequent carcinoma of the extra hepatic biliary tract. Symptoms are non-specific and the diagnosis is often made at an advanced stage at operation for routine cholecystectomy. In our study 450 patients who underwent Cholecystectomy, incidental gall bladder carcinoma was diagnosed histo-pathologically in 3 cases. All patients were female. Nausea, vomiting and pain in the right upper quadrant (RUQ) of the abdomen were the common clinical presentation in all three cases.

The incidence of gall bladder carcinoma was found of $0.67 \%$, with the mean age $38.33 y r s$. and 10.60 standard deviation. Similar to the incidence in other studies in published literature. The risk factor widely related to the gall bladder cancer are advanced age 
and gall stones disease. All three patients were female and risk factors of Gall bladder cancer increases with increasing size of gall stones - patients with larger stones ( $>3 \mathrm{~cm}$.) have about a ten

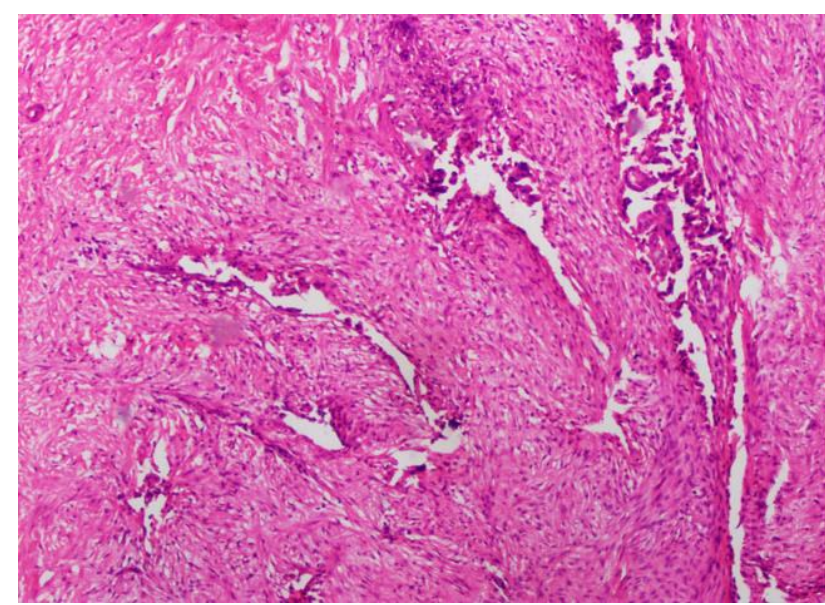

Fig 6: Microscopic feature: Histomorphological features shows moderately differentiated adenocarcinoma infiltrating in to muscle layer. image $4 x$

In our study 2 cases were in well differentiated adeno-carcinoms, in Grade 1 and TNM staging T1b Nx Mx with the pragnosis of 90$100 \%$ in the age of $30-40 \mathrm{yrs}$. and one cases was in Moderately differentiated Adenocarcinoma, in grade 2 and TNM staging pT2 NX MX with the prognosis of $47 \%$ in the age of 48 age.

The therapeutic approach to gall bladder carcinoma is applied according to the stages of tumor. Systematic review of IGBC from a prognostic point of view, Ro resection is the most important positive factor for overall survival of GB cancer. ${ }^{1,2}$ The extent of surgery is different according to the depth of invasion (T Stage) of tumors. For a pT1a Tumor, Cholecystectomy is the standard procedure whereas for a $\mathrm{pT} 1 \mathrm{~b}$ tumor, cholecystetomy with lymph node dissection has been performed. For $\mathrm{pT}_{2}$ and more advanced tumors, liver resection including the gall bladder bed and lymph node dissection are recommended. Extra hepatic bile duct resection is not performed uniformly.

Therefore, approximately three quarters of patients with Incidental GB cancer were ultimately candidates for revisional surgery. Simple cholecystectomy may be sufficient for patient with pT1a tumors by the TNM classification with cure rates ranging from 73 to $100 \%$ and for $\mathrm{pT} 1 \mathrm{~b}$ tumors (Tumor invading the muscular layer) the benefit of radical resection is controversial.

The site specific prognostic factors include histological type, histological grade and lymphovascular invasion. Papillary carcinoma have most favorable prognosis un favorable prognosis includes small cell carcinoma and undifferentiated carcinoma and lymphovascular invasion.

The importance of a histological examination of the post cholecystectomy specimens cannot be over emphasized. The non-specific clinical features and sonographic findings of early GBC make the preoperative diagnosis difficult and an incidental $G B C$ has been recorded in every reported series of laparoscopic cholecystectomy cases.

\section{CONCLUSION}

The incidence of incidental gall bladder cancer has been reported to very up to $2.85 \%$. Female gender and advanced age are demographic risk factors for gall bladder cancer. Gall bladder times higher risk of having GBC as compared to those with smaller $<1 \mathrm{~cm}$.) stones. Patients with GBC are around $15-20$ years older than patients with gall stones.

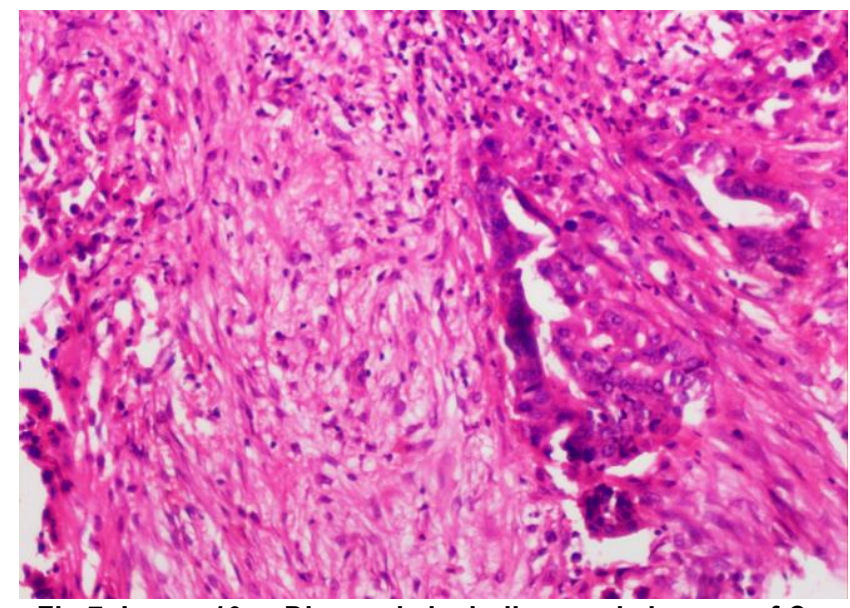

Fig 7: Image $10 \mathrm{x}$ : Diagnosis including grade in case of $\mathrm{Ca}$ GB - Grade -2, Pathologic stage [AJCC2010]TNM - pT2 NX MX

cancer risk a short course with a poor prognosis, incidentally diagnosed tumors are often found in early stage and have a better prognosis.

\section{REFERENCES}

1. Weinstein D, Herbert M, Bendet N, Sandbank J, Halevy A. Incidental finding of gall bladder carcinoma. IMAJ 2002; 4:334336.

2. Jin K, Lan H, Zhu T, He K, Teng L. Gall bladder carcinoma encountered during laproscopic cholecystectomy. Clin Transl Oncol 2011; 13:25-33.

3. Shrestha R, Tiwari M, Ranabhat S K, Aryal G, Rauniyan S K, Shrestha H G. incidental gall bladder carcinoma : value of routine histological examination of cholecystectomy specimens. Nepal Med Coll J 2010; 12:90-94.

4. Youssef F, Khan A W, Davidson B R. Disseminated bony metastases following incidental gall bladder cancer detected after laproscopic cholecystectomy. J Hep Pancreat Billi 2003; 5:258260.

5. Malik KH, Jawaid M. Incidental gall bladder carcinoma in patients undergoing cholecystectomy for Cholelithiasis. Pak J Surg 2009;25:262-265.

6. Ghimire P, Yogi N, Shrestha BB. Incidental carcinoma gall bladder in case of routine cholecystectomy. Kathmandu Uni Med J 2011:9:3-6.

7. Akyüreck $N$, İrkörücü $O$, Salman $B$, Erdem $O$, Sare $M$, Tatliciog̉lu. Unsuspected gall cancer during laproscopic cholecystectomy. JHB Surg 2004; 11:357-361.

8. Tantia O, Jain M, Khanna S, Sen B. Incidental laproscopic cholecystectomy for symptomatic gall stone disease. Surg Endosc 2009; 23:2041-2046.

9. Cotoni S, Dalla Valle R, Zinicola R. Unsuspected gall bladder cancer after laproscopic cholecystectomy. An emerging problem? Reflection of four cases. Surg Endosc 1999; 13:264-267.

10. Targarona EM, Pons MJ, Viella $P$, Trias M. unsuspected carcinoma of gall bladder. Surg Endosc 1994; 8:211-213.

11. Shukla PJ, Barreto G, Kakade A, Shrikhande SV. Revision surgery for incidental gall bladder cancer: factors influencing 
operability and further evidence for T1b cancer. HPB 2008; 10:4347.

12. Batra YP, Pal S, Dutta U, Desai $P$, Garg $P$ k, Makharia $G$, Ahiya V, Pande G K, Sahni $P$ et al. gall bladder cancer in India: A dismal picture. J Gastroenterol Hepatol 2005; 20:309-314.

13. Kaul V, wani N A, Pajor $Y D$, Primary carcinoma of gall bladder - a review of thirty six cases. Ind J Pathol Microbiol 1989; 32:146-151.

14. GENC V, Kirimker EO, Akyol C, Koccay A T, Korabork A, Tuzuner A Erden E , Karayakin K. incidental gall bladder cancer diagnosed during or after laproscopic cholecystectomyin members of the Turkish population with gall stone disease. Turk J Gastroenterol 2011; 22:513-516.

15. Lobo L, Prasad K, Satoskar RR. Carcinoma of the gall bladder: A prospective study in a tertiary hospital of Bombay, India. J Clin Diag Res 2012; 6:692-695.

16. Jetley S, Rana S. Khan S, Hassan M J, Zeba S J. Incidental finding of gall bladder carcinoma in laproscopic cholecystectomy: A report of 6 cases and a review of the literature. J Clin Diag Res 2013; 7:85-88.

17. Ramesh S Waghmare, Rima N Kamat. Incidental gall bladder carcinoma in patients undergoing cholecystectomy -A Report of 7 cases. JAPI September 2014 volume 62.
18. Hanni V Gulvani, Sunita Gupta, et al, Incidental detection of gall bladder carcinoma in laparoscopic cholecystectomy specimens- A 13 years study of 23 cases and literature review. Indian J Surg Onco 2015; 6(1) 30-35.

19. Aditi Raina Malay Bajpai, Incidental gall bladder carcinoma A Retrospective study. IOSR JDMS, Volume 15 (2016) 114-116

\section{Source of Support: Nil.}

Conflict of Interest: None Declared.

Copyright: () the author(s) and publisher. IJMRP is an official publication of Ibn Sina Academy of Medieval Medicine \& Sciences, registered in 2001 under Indian Trusts Act, 1882.

This is an open access article distributed under the terms of the Creative Commons Attribution Non-commercial License, which permits unrestricted non-commercial use, distribution, and reproduction in any medium, provided the original work is properly cited.

Cite this article as: Mangilal Choudhary, Dilip Ramrakhiani. Incidental Gall Bladder Carcinoma in Patients Undergoing Cholecystectomy in a Tertiary Care Hospital. Int J Med Res Prof. 2016; 2(6):42-45. DOI:10.21276/ijmrp.2016.2.6.008 